\title{
Potential landslide territories and their functional use in the Chechen Republic
}

\author{
Rustam Gakaev* \\ Chechen State University named after A.A.Kadyrov, 364024, st. Sheripova, 32, Grozny, Russia
}

\begin{abstract}
Each type of natural phenomenon manifests itself in certain conditions at a certain period of time and in a certain territory. For example, for mountainous areas such natural phenomena as mudflows, avalanches, earthquakes are most typical, and for the plains - dust storms, floods. But those and other phenomena can occur on the plains and in the mountains, but the consequences will be different. For example, the slowflowing water during flooding on the plains and the seething streams of mountain rivers can lead to various negative consequences. Knowledge of the features of natural phenomena and processes makes it possible to prepare in advance for a predicted situation and take measures, which greatly reduces the possible risk. This paper discusses the features of the manifestation of exogenous geological processes characteristic of the mountainous part of the Chechen Republic.
\end{abstract}

\section{Introduction}

The mountainous part of the Argun river basin, with the greatest activation of landslide processes, is located south of the Chechen foothill plain, occupies the central part of the mountainous territory of the Chechen Republic. The territory is characterized by a highly dissected relief and soft, flowing outlines. The mountain slopes are relatively gentle, the peaks are smoothed. Only in some places is some asymmetry observed in the transverse profile of the longitudinal valleys. The somewhat steepness of their southern slopes indicates a monoclinal structure. Absolute heights from 350-400 to 800-1200 meters above sea level. The main relief forms of the Black Mountains are the meridional or close to it direction of the ridges [16-17]. They rise gradually to the south and usually represent rather narrow watersheds between the transverse valleys of two neighboring rivers. These ridges owe their formation to river erosion, and their general direction does not coincide with the strike of the tectonic structures of the region. At the mouths of gullies and gorges overlooking the Chechen Plain, or terraces of mountain rivers, there are significant fan loops. Quite intensive landslide processes have developed here [3].

The complexity of the orography, hydrography, climate and geological structure of the territory of Mountainous Chechnya determines the high probability of landslide processes

\footnotetext{
* Corresponding author: rustam.geofak@yandex.ru
} 
and in the future, which pose a threat to the life and health of the population, cause significant damage to the economy of the republic.

As a rule, from the point of view of topography and geomorphology, the moderately gentle relief with a steep summit is prone to landslide development. As for the geological background, the development of landslides is mainly influenced by the angle of inclination of the layers and the geological structure. Different layers have different hardness, density and susceptibility to weathering, as well as the contribution of the material to landslide. Slope irregularities caused by a fracture in the plane of the structure create conditions for the occurrence of landslides. Hydrological conditions are the main determinants of landslide development. The difference between active landslides and landslides caused by rain is the softening of rocks and soil caused by prolonged exposure to surface water and groundwater, which reduces the strength of rocks and soil, creates hydrodynamic pressure and pore water pressure, increases the volume of rock density and soil mass, and creates buoyancy forces on permeable formations, especially on the sliding surface (zone), which reduces the strength of the composite. Changes in land cover and the impact of human activities also contribute to the formation of landslides, especially the destruction of vegetation, excavation at the base of the slope, the accumulation of slopes and other hazardous human engineering work, which are among the important factors affecting the occurrence of landslides [7-8].

The role of climatic conditions in landslide formation is clearly expressed in various landslide regions and in addition to the Caucasus. For the development of landslide processes, the most favorable are areas of a humid climate with a uniform precipitation regime, which are also characterized by drizzling rains. Under such conditions, rocks on the slopes are deeply soaked and saturated with water as much as possible.

Based on a reconnaissance study of the Chechen Republic, he calculated that at least $75 \%$ of all landslides were natural [3].

Early detection of potential landslide hazards is of great practical importance for early warning and prevention of natural disasters. The study used a variety of machine learning techniques to identify potential active landslides along a 15-kilometer buffer zone on both sides of the Black Mountains processes. Thus, the study offers the best solution to distinguish which areas of deformation accumulation pose a risk of landslides, and which are not landslide, based on surface deformation and the factors of landslide influence, which is a more complex problem [4]. Compared to traditional methods, machine learning can match complex multiple interactions or nonlinear relationships, resulting in higher prediction accuracy. This study is based on a comparative study of various machine learning algorithms in the field of attribute selection and parameter optimization. Although landslide predictions provide some accuracy, the results of different models for landslide identification are subject to spatio-temporal discrepancies due to different input variables and the theoretical basis of the algorithm; and therefore uncertainties. Uncertainties in the results of various models of landslide identification create problems when choosing the most appropriate management method for this complex natural phenomenon. To reduce these uncertainties, in the future, the study will conduct further research on the automatic identification of areas of accumulation of surface deformations, which determines the basis for the potential accuracy of recognition of active landslides.

Landslide exposure mapping is a very important tool for identifying potential landslideprone areas. In this paper, the weight of evidence method is used to derive an estimate of the exposure to landslides. The weight of evidence model is commonly used in landslide research because it is widely accepted and easy to use. In total, after the landslide inventory, 84 landslides were identified. Thematic layers of all causal factors and existing landslides are prepared in Arc GISsoftware. Mostly digital elevation model (DEM) causal 
factors and field data were used to prepare causal data layers. In this study, internal factors were used to assess landslides. Aspects facing southeast and east, inclination $>60$ degrees, elevation differences of 1300-1700 m, filitic rocks and agricultural land followed by forests are the main sources of landslide hazards in the study area. The weight of evidence model was validated using the area under the curve method. The success curve showed an accuracy of $73.16 \%$. It can be concluded that the weight of evidence model is a suitable model for analyzing susceptibility to landslides, and the area is highly prone to landslides.

\section{Research methodology}

Landslide hazard assessment was studied using a set of interrelated methods [1-3]:

- Study of regulatory and methodological documentation regulating topographic and engineering-geological surveys on landslide ridges and analysis of technical literature;

- Collection and analysis of cartographic materials for the study area in order to identify landslide-forming factors;

- Cartographic (geoinformation) modeling of landslide-forming factors;

- Statistical analysis of the results obtained to draw up a map of the zoning of the territory in accordance with its landslide potential.

Landslide susceptibility assessment aims at differentiating the land surface into homogeneous areas according to their likelihood of destruction caused by massive displacement at a specific location. A physically based landslide susceptibility model can simultaneously perform temporal and spatial predictions of landslides, which can determine when and where a landslide occurred. will happen, but susceptibility maps are used to estimate where a landslide should be expected, Brabb said, they do not contain any temporal information about when it will occur. A susceptibility map can be prepared in GIS using statistical, heuristic or physical methods. Heuristics are used to assign weights to predisposing factors, also known as causal factors or levels of evidence, based on expert experience, while in statistical methods based on data, weights are obtained by comparing landslide incidents and layers of evidence using both options. and multidimensional methods. Commonly used bivariate methods are information value and evidence weights modeling, in which the weights for each parameter are derived from the landslide inventory. The weight of evidence model has many advantages over other statistical methods. Evidence weights is a data-driven approach that is basically a Bayesian approach in log-linear form using prior and posterior probabilities and is applied where there is sufficient data to estimate the relative importance of the evidence topics using statistical means.

In the field of landslide research, early detection of potential landslide hazards is a hot but challenging topic $[3,4]$. In general, landslides have obvious spatial and temporal characteristics. Spatially, the study of landslides can be considered on a regional and point scale. Temporarily, the study of landslides can be focused either on the time when they occurred, or on the potential hazards of landslides [4-6]. Regional studies mainly focus on three aspects: landslide detection, historical cataloging of landslides, and assessing the risk of landslides at the regional level. These regional-scale studies are based on spectral characteristics, spatial characteristics, morphological attributes and contextual landslide information derived from remote sensing images from multiple sources. These studies often use object-oriented methods, SVM, RF and other machine learning methods to identify the occurrence of landslides and catalog them; regional landslide risk is then assessed using a variety of machine learning and ensemble learning models by modeling and analyzing the importance of factors influencing landslide cataloging and generating landslide 
susceptibility maps. Point-scale studies focus on retrospective analysis of the spatiotemporal evolution of a specific landslide disaster and provide data for emergency monitoring and landslide disaster analysis. These studies are more often based on optical or radar remote sensing and are useful for monitoring and early warning of the risks of landslide disasters, disaster evolution, creep characteristics before disasters and secondary hazards after disasters $[6,13,14]$. In recent years, due to significant advances in InSAR technology in monitoring surface deformations, research has begun to use re-orbital radar interferometry time series to study regional active landslide hazards and obtain data on potential landslide hazards through human-computer interaction. interpretation $[15,16]$. However, previous studies often did not use the analysis of data from InSAR deformation results and all factors influencing the potential hazard of active landslides, and did not establish a relationship between the degree of surface deformation and causal factors, since the identification of active landslides based on deformation results was more complete by interpreting the interaction. human and computer. Machine learning can provide a better solution to discern which areas of deformation accumulation pose a landslide hazard and are not associated with landslides, which is a more complex problem. Compared to traditional methods, machine learning methods can correspond to complex multiple interactions or nonlinear relationships, resulting in higher prediction accuracy. Machine learning methods are often a good addition to traditional statistical methods and even in many cases a good substitute. In addition, studies show that compared to statistical regression or machine learning models, ensemble learning can improve the accuracy of landslide sensitivity mapping to a certain extent, which requires more complex optimization and model adjustments. At the same time, different methods have large differences in data sampling, choice of influencing factors, parameter setting, reliability and generalization of the model [10].

A pressing issue in landslide monitoring and risk assessment is defining how to analyze and identify landslide risk factors using machine learning for remote sensing from multiple sources, basic geography and geological data, and how to create or select recognition models for early warning of potential landslide hazards based on deformation data.

\section{Results and Discussions}

High-resolution Google Earth images were used as the main sources for the landslide inventory map. A digitized landslide boundary map was created with visual interpretation of Google Earth images. Landslides, including areas of scar and sediment, have been converted to landfills. Landslide polygon digital data was imported into Arc GIS 10.2 for analysis. The landslide polygons were projected in the lateral Mercator direction $82{ }^{\circ}$ east of the central meridian (WGS 1984 zero). This projection system was applied to the entire survey area database. Then the vector was transformed into a raster to obtain raster data on landslide areas with a cell size of $12.5 \mathrm{~m}$ (DEM) [13].

The inventory showed 84 landslides with an area of $293797 \mathrm{~m} 2$. On an area of 125.66 $\mathrm{km} 2$, the density of landslides was 0.66 per $1 \mathrm{~km} 2$. Most of the landslides were concentrated on arable land and areas devoid of vegetation or forest [14]. They were selected at random to represent the entire catchment.

There is an engineering classification of slopes as stable (or) unstable. The hillsides can be stable or unstable. Slope instability arises from the relationship between overburden and bedrock. It also depends on the limiting angles that control the geomorphic process affecting it. Stable slopes below the limiting angle of motion of the masses. They usually range from 38 to 40 degrees. Slope instability arises from geological, geomorphological 
and hydrological conditions. These include hillside processes, vegetation changes, landau practice, human activities, rainfall frequency and intensity, and local seismicity, if any. The forces acting on the slopes are two-fold as the driving force (or) the resistance force. A landslide occurs when the driving force is greater than the drag force. Everything happens under the influence of gravity. The increase in driving forces (weight of the slope) can occur due to the addition of water or the addition of structures. The decrease in drag forces can be due to a decrease in weight at the bottom of the slope or excessive slope, or due to the removal of the base of the slope, or due to a decrease in frictional energy, or due to the addition of water, which can lubricate and reduce the strength of the rock.

\section{Conclusions}

Thus, geographic information systems make it possible to assess the landslide hazard of territories, which is necessary for their safe development. The proposed technique can be included in the initial planning stage, and its implementation in practice is possible using cartographic materials obtained as a result of engineering surveys. When maintaining survey databases in GIS, labor costs for assessing the risk of landslides are reduced because there is no need to collect and digitize relevant cartographic materials.

Landslides are ubiquitous in the hills, mountains and high coasts that form land masses, and in many areas they cause significant human, social, economic and environmental damage and costs. Thus, reliable prediction of landslides and their consequences is of paramount importance. As with other natural hazards, landslide forecasting involves predicting "where" landslides can be expected (spatial forecasting), "when" or how often they can be expected (temporal forecast) and "how many", how large or destructive. it should be expected that landslides will be in the area (number, size, impact, forecast of destructiveness). The combined expectation of "where", "when" (or how often) and "how big" or destructive the landslide will be is called "landslide hazard". Unlike other natural hazards, two different types of forecasts are possible for landslides, namely: (i) forecasting individual landslides, i.e. predicting the behavior of one slope or part of it, and (ii) forecasting populations of landslides, i.e. forecasting the behavior of many (from tens to several tens of thousands) landslides occurring on the territory, and their spatial and temporal evolution [17].

\section{References}

1. V. V. Bardyuk, L.S. Stoyko, On the issue of an integrated assessment of the quality of surface waters (2020)

2. G. A. Bogdanovsky, Chemical Ecology (2018)

3. O. M. Mazur, Engineering Ecology, 315 (2020)

4. Ya. P. Molchanova, Hydrochemical indicators of the state of the environment (2019)

5. J. J. Andrea, C. Burns, J. Touza, Renewable Energy as a Luxury? A Qualitative Comparative Analysis of the Role of the Economy in the EU's Renewable Energy Transitions During the 'Double Crisis', Ecological Economics, 142, 81-90 (2020)

6. J. Yang, F. Zhang, X. Jiang, W. Sun, Strategic Flexibility, Green Management, and Firm Competitiveness in an Emerging Economy, Technological Forecasting and Social Change, 101, 347-356 (2018) 
7. H. B. Dulal, R. Dulal, P. K. Yadav, Delivering Green Economy in Asia: The Role of Fiscal Instruments. Futures, 73, 61-77 (2019)

8. J. Mauritzen, Contractors and Scale: An Empirical Analysis of the California Solar Market (2020)

9. J. Meckling, L. Hughes, Protecting Solar: Global Supply Chains and Business Power, New Political Economy, 23(1), 88-104 (2020)

10. S. D. Belyaev, Using water quality targets in water management planning (2020)

11. A. M. Vladimirov, F. A. Imanov, Principles for assessing the ecological flow of rivers (2019)

12. F. Imanov, M. Ya. Asadov, Assessment of water resources and ecological state of the Samur River (2019)

13. A. N. Elizariev, T. B. Fashchevskaya, Assessment of water potential using GIS technologies (2018)

14. V. P. Emelyanova, G. N. Danilova, T. Kh. Kolesnikova, Assessment of the quality of land surface waters by hydrochemical indicators (2020)

15. A. A. Daukaev, R. Kh. Dadashev, L. S. Gatsaeva, R. A. Gakaev, Landslides and mudflows in the Chechen Republic: synergetic aspects, 63 (2019)

16. R. A. Gakaev, I. A. Bayrakov, Geomorphological conditions of landslide formation in the Itum-Kalinskaya depression of the Chechen Republic (2018)

17. A. A. Daukaev, R. Kh. Dadashev, L. S. Gatsaeva, R. A. Gakaev, Landslides and mudflows in the Chechen Republic: synergetic aspects, 84-86 (2019) 